\title{
Digital veneering system enhances microtensile bond strength at zirconia core- veneer interface
}

\author{
Ki-Yeon KIM ${ }^{1, *}$, Taek-Ka KWON²,*, Tae-Joo KANG ${ }^{3}$, Jae-Ho YANG ${ }^{1}$, Shin-Jae LEE ${ }^{3}$ and In-Sung YEO ${ }^{1}$ \\ ${ }^{1}$ Department of Prosthodontics, School of Dentistry and Dental Research Institute, Seoul National University, 101 Daehak-ro, Jongno-gu, Seoul \\ 110-749, Korea \\ ${ }^{2}$ Department of Dentistry, St. Catholic Hospital, The Catholic University of Korea, 93 Jungbu-daero, Paldal-gu, Suwon 442-723, Korea \\ ${ }^{3}$ Department of Orthodontics, School of Dentistry, Seoul National University, 101 Daehak-ro, Jongno-gu, Seoul 110-749, Korea \\ Corresponding author, In-Sung YEO; E-mail: pros53@snu.ac.kr
}

\begin{abstract}
This study investigated the effect of digital veneering system (DVS) on strengthening the bond between a zirconia core and ceramic veneer. Specimens for Groups 1 (negative control), 2 (positive control), 3, and 4 used conventional porcelain veneering technique on untreated, sandblasted, coloring agent-treated, and modifier-treated zirconia cores respectively. Group 5 used DVS, where glass ceramic veneers — produced by computer-aided milling - were fused to zirconia cores. Microtensile bond strengths (MTBS) at the interface were measured. MTBS results of Groups 1 to 5, expressed in mean (standard deviation), were 28.1 (7.3), 27.8 (6.3), 30.0 (10.2), 32.9 (8.1), and 37.8 (8.1) MPa. The DVS group had significantly higher MTBS than the negative and positive controls ( $p<0.05)$. Results showed that DVS enhanced the bond strength between zirconia core and ceramic veneer, indicating that this system could reduce adhesive failure-related complications that frequently occur at the zirconia core-veneer interface.
\end{abstract}

Keywords: Microtensile bond strength, Digital veneering system, Adhesive failure, Zirconia restoration, Surface pretreatment

\section{INTRODUCTION}

Most failures in all-ceramic zirconia restorations occur at the interface between the zirconia core and ceramic veneer, despite the structural stability of zirconia cores $^{1-5)}$. Prevalence of such interfacial failures leads to the clinical application of monolithic zirconia. However, some properties of monolithic zirconia need to be improved - such as relative opacity, monochromatic appearance, and color change after polishing and glazing; although recent reports on esthetically acceptable monolithic zirconia have emerged ${ }^{6-8)}$. For acceptable esthetic appeal, it is recommended that zirconia cores be veneered with dental and enamel porcelains.

Sufficient bond strength between the ceramic veneer and zirconia substructure is essential for the long-term clinical success of zirconia restorations. Core-veneer bond strength is determined by various factors including mechanical interlocking, strength of chemical bonding between the core and veneer, wetting properties, and transformation of zirconia crystals at the core-veneer interface due to thermal influences ${ }^{9.11}$. There has been considerable research on the effects of zirconia cores' coloring agents, veneering materials, surface treatments, and veneering methods on core-veneer bond strength ${ }^{12-15)}$. Some techniques that involve the use of coloring agents and multiple firings of veneering porcelains have been reported to negatively affect the bond strength between zirconia cores and veneering materials ${ }^{13,16)}$.

To overcome such a problem, the digital veneering system (DVS) was introduced. DVS-based crowns are made up of three components: zirconia coping, fusion

*Authors who contributed equally to this work.

Received Jun 6, 2014: Accepted Jul 14, 2014

doi:10.4012/dmj.2014-168 JOI JST.JSTAGE/dmj/2014-168 porcelain, and milled glass ceramic veneer. Each component is available in different shades and degrees of translucency. With glass ceramic blocks available in enamel colors and fusion porcelains in dentin colors, DVS could produce veneers that are esthetically similar to natural teeth. The use of dentin-colored fusion porcelain and enamel-colored milled glass ceramic minimizes the number of firings of zirconia cores and thus maintains core-veneer bond strength without compromising esthetics ${ }^{17}$. Incidentally, it becomes necessary to evaluate core-veneer bond strength achieved by DVS system and compare it against the other existing methods.

The aim of this study was to investigate the effects of various surface treatments, including the DVS process, on bond strength between zirconia cores and ceramic veneers. The null hypothesis underlying this investigation was that there would be no significant differences in bond strength among the treatment techniques.

\section{MATERIALS AND METHODS}

Preparation of zirconia core-ceramic veneer specimens Table 1 lists the materials used in this study. Groups 1 to 4 used feldspathic porcelain (Lava Ceram, 3M ESPE, Seefeld, Germany) for the veneering ceramic, while Group 5 used DVS-based ceramic blocks (Lava DVS ceramic, 3M ESPE, Seefeld, Germany). Zirconia block (Lava zirconia, 3M ESPE, Seefeld, Germany) was cut into disks (24.4 $\mathrm{mm}$ diameter, $5 \mathrm{~mm}$ thickness) using a diamond saw under water cooling and then sintered according to manufacturer's instructions. After sintering, the zirconia disks shrank to a diameter of $19.5 \mathrm{~mm}$ and a thickness of $4 \mathrm{~mm}$. 
Table 1 Properties of materials as provided by the manufacturer

\begin{tabular}{|c|c|c|}
\hline Material* & Composition & $\mathrm{CTE}^{\dagger}\left(\times 10^{-6} /{ }^{\circ} \mathrm{C}\right)$ \\
\hline Lava zirconia & Zirconium oxide $79-97 \%$, yttrium oxide $3-15 \%$, Hafnium oxide $<5 \%$ & $10.5 \pm 0.2$ \\
\hline Lava Ceram & $\begin{array}{l}\text { Silicon dioxide } 60-70 \% \text {, Aluminum oxide } 9-13 \% \text {, Lithium oxide }<1 \% \text {, } \\
\text { Calcium oxide } 2-5 \% \text {, Barium oxide } 1-2 \% \text {, Zirconium oxide }<1 \%\end{array}$ & 9.5 \\
\hline Lava DVS ceramic & Oxide glass chemicals $95-99.9 \%$, Quartz silica $<0.1 \%$ & $9.2 \pm 0.3$ \\
\hline Coloring agent & $\begin{array}{c}\text { Water }>84 \% \text {, Polyethylene glycol } 1-10 \% \text {, Erbium chloride } 1-10 \% \text {, } \\
\text { Iron chloride }<2 \%\end{array}$ & - \\
\hline Lava framework modifier & $\begin{array}{l}\text { Silicon dioxide } 60-70 \% \text {, Aluminum oxide } 9-13 \% \text {, Lithium oxide }<1 \% \text {, } \\
\text { Calcium oxide } 2-5 \% \text {, Barium oxide } 1-2 \% \text {, Zirconium oxide }<1 \%\end{array}$ & 9.5 \\
\hline DVS fusion porcelain & $\begin{array}{c}\text { Oxide glass chemicals } 95-99.9 \% \text {, Quartz silica } 0-0.5 \% \text {, } \\
\text { Nickel iron chromite black spinel } 0-0.01 \%\end{array}$ & $9.2 \pm 0.3$ \\
\hline
\end{tabular}

* All the materials in this table were from 3M ESPE (Seefeld, Germany).

${ }^{\dagger} \mathrm{CTE}$ : Coefficient of thermal expansion

Table 2 Zirconia surface treatments and veneering methods

\begin{tabular}{lccc}
\hline & Zirconia surface treatment & Veneering ceramic & Veneering method \\
\hline Group 1 (Control, negative) & No treatment & Lava Ceram & Manual layering \\
Group 2 (Control, positive) & Sandblasting & Lava Ceram & Manual layering \\
Group 3 (Coloring agent) & Coloring & Lava Ceram & Manual layering \\
Group 4 (Modifier) & Modifier & Lava Ceram & Manual layering \\
Group 5 (DVS) & No treatment & Lava DVS glass ceramic & Milling and fusion with \\
\end{tabular}

Zirconia disk specimens were divided into five groups (Table 2). Group 1, which served as negative control, comprised zirconia disks without any surface treatment. Group 2, which served as positive control, comprised zirconia disks that had been sandblasted with $110-\mu \mathrm{m}$ aluminum oxide particles at a pressure of 2.7 bar and then cleaned ultrasonically. Group 3 comprised colored zirconia disks (shade A1) which had been processed by dipping in a coloring solution (Coloring agent, 3M ESPE, Seefeld, Germany) before the sintering process. Group 4 comprised zirconia disks treated with a modifier (Lava framework modifier, 3M ESPE, Seefeld, Germany). The intended use of the modifier was to mask the white color of zirconia and improve the bond strength between zirconia core and ceramic veneer ${ }^{12)}$. In Groups 1 to 4 , two layers of veneers - which were fired in a furnace and of $2 \mathrm{~mm}$ thickness per layer- were applied to each zirconia disk in two steps by an expert dental technician according to manufacturer's instructions.

In Group 5, zirconia disks were veneered with 4-mmthick Lava DVS glass ceramic. These materials were fused together using a fusion porcelain (DVS Fusion Porcelain, 3M ESPE, Seefeld, Germany) (Table 2).

For Groups 1 to 5, final thickness of all zirconia coreceramic veneer specimens was $8 \mathrm{~mm}$.
Microtensile bond strength (MTBS) test

A core-veneer specimen from each of the five groups was sectioned into at least 50 microbars $\left(1 \times 1 \times 8 \mathrm{~mm}^{3}\right)$ using a diamond-coated saw (Ehwa Diamond Industrial Co., Ltd., Osan, Korea) under copious water irrigation (Fig. 1a). No additional trimming was performed after the cutting procedure. The microbars were examined using a stereomicroscope (MZ6, Leica Microsystems GmbH, Wetzlar, Germany) at $\times 20$ magnification, and defective specimens were excluded. Eighteen sound microbars were selected from each group for the microtensile bond strength (MTBS) test.

Selected microbars were fixed to an MTBS testing apparatus using a self-adhesive resin (Clearfil SA Luting, Kuraray Medical Inc., Okayama, Japan). The MTBS testing apparatus was a jig specially designed for the MTBS test (Figs. 1b, 1c). After a microbar specimen was attached to the jig, the latter was connected to a universal testing machine (Instron 8848 Microtester, Instron $^{\circledR}$ Co., Norwood, USA) which operated at a crosshead speed of $1 \mathrm{~mm} / \mathrm{min}$ with a load cell of $1 \mathrm{kN}$. Peak value at failure was recorded. Obtained values in Newton (N) units were converted to equivalent values in $\mathrm{MPa}$ units through the formula, MTBS $(\mathrm{MPa})=\operatorname{Load}(\mathrm{N}) /$ Area $\left(\mathrm{mm}^{2}\right)$. Cross-sectional areas of the microbars were 


\section{(a)}
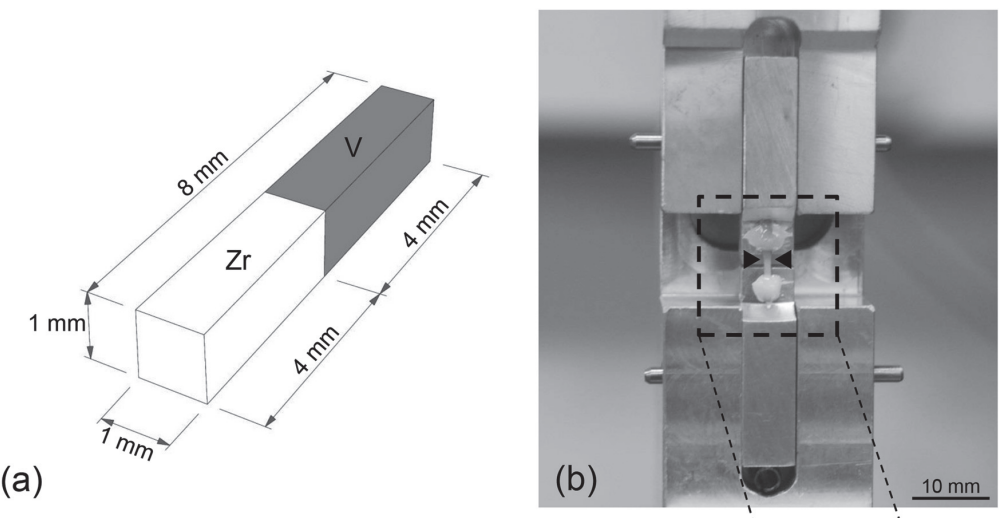

(c)
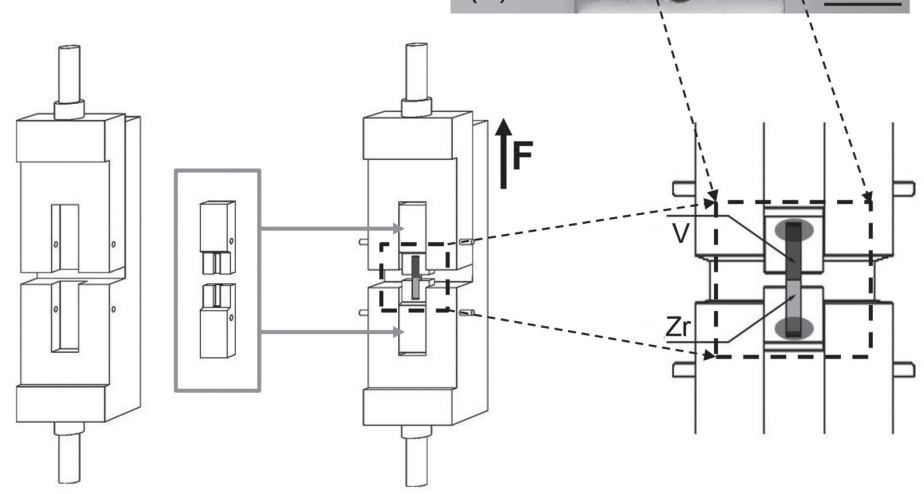

Fig. 1 (a) Dimensions of the microbar specimen. (b) Microbar was attached to MTBS testing apparatus using a self-curing resin. Core-veneer interface of microbar was clear and not contaminated with adhesive (black arrowheads). (c) The jig, specially designed for the MTBS test, had three parts. The first part, the base (leftmost), was designed to connect to the universal testing machine. The second part (in grey rectangle) was on top of the base (grey arrows) and enabled resistance-free up and down movements through a specially made bearing. The third part (in dashed squares), to which a specimen was attached using the adhesive, had a furrow of $1.1 \times 1.1 \mathrm{~mm}$. A pair of these parts was used for each specimen. After the second and third parts were connected to the base, stress was applied to the specimen ( $\mathrm{F}$, the direction of applied stress, is shown in the middle). Zr: zirconia core; V: ceramic veneer.

measured using a digital caliper (Mitutoyo, Kawasaki, Japan).

\section{Fracture surface analysis}

Before the MTBS test, specimens were observed using a scanning electron microscope (SEM; Nova NanoSEM 230, FEI Co., Eindhoven, NL). After the test, broken microbars were carefully removed from the attachment unit. Using the aforementioned stereomicroscope, the zirconia surfaces were examined at $\times 30$ magnification to determine their failure modes. Failure mode was classified as cohesive when it occurred within the veneer, adhesive when it occurred between the core and veneer, and mixed when both cohesive and adhesive failures were observed.

Specimens whose failure modes were indeterminable under the stereomicroscope were rinsed with $96 \%$ ethanol, air-dried, mounted on metallic stubs, sputtercoated with gold (K650Xt, EM Technologies Ltd., UK), and examined again using SEM at $\times 100, \times 200$, and $\times 2000$ magnifications.

Chemical compositions of the fractured surfaces of specimens were analyzed using energy dispersive spectroscopy (EDS; Genesis Apex, EDAX Inc., Mahwah, NJ, USA).

\section{Statistical analysis}

MTBS data did not fulfill the parametric conditions of normality or equality of variance according to D'Agostino normality test and Breusch-Pagan test against heteroscedasticity. The Kruskal-Wallis rank sum test was performed when there was a significant betweengroup difference, and the Wilcoxon test was used to find significant differences between two groups. The Bonferroni correction was applied to counteract multiple comparisons. Data were analyzed at a confidence level of $95 \%$. 
Table 3 Mean and standard deviation (SD) of microtensile bond strength (MTBS) and failure mode of the different test groups

\begin{tabular}{lll}
\hline \multicolumn{1}{c}{ Group } & MTBS* (SD) & Failure mode \\
\hline 1 (No treatment) & $28.1(7.3)$ & $78 \%$ cohesive, $22 \%$ mixed \\
2 (Sandblasting) & $27.8(6.3)$ & $94 \%$ cohesive, $6 \%$ mixed \\
3 (Coloring) & $30.0(10.2)$ & $100 \%$ cohesive \\
4 (Modifier) & $32.9(8.1)$ & $94 \%$ cohesive, $6 \%$ mixed \\
5 (DVS) & $37.8^{\dagger}(8.1)$ & $94 \%$ cohesive, $6 \%$ mixed \\
\hline
\end{tabular}

*Unit: $\mathrm{MPa}$

${ }^{\dagger}$ Group 5 showed a significantly greater MTBS value than those of groups 1 and 2.

\section{RESULTS}

Table 3 shows the means and standard deviations (SD) of peak MTBS values at failure. Group 5, which used DVS, had a mean MTBS value significantly different from those of negative and positive controls $(p<0.05)$. Using the Wilcoxon test, no other sets of groups showed any statistically significant difference in MTBS (Fig. 2).

Figure 3 shows the representative SEM images acquired in this study. Lower-magnification images provided an overview of each microbar, while highermagnification images revealed the quality of the bonding interface as well as the presence of various structural defects in each specimen.

Most specimens showed clear cohesive failure of the veneering ceramic (Table 3). None of the specimens showed complete detachment of the ceramic veneer, which would result in exposure of the entire zirconia core. However, four specimens from Group 1 and one specimen each from Groups 2, 4, and 5 showed failure of the mixed type: the zirconia core was slightly exposed and a thin layer of the ceramic veneer remained on the zirconia core surface (Fig. 3).

\section{DISCUSSION}

The DVS group (Group 5) showed tensile strengths that were significantly greater than those of both positive and negative controls, which used conventional ceramic veneering technique. According to SEM observations, specimens veneered with DVS-based glass ceramic showed noticeably fewer bubbles at the interface or within the ceramic, which might thus result in greater adhesive and cohesive strengths. Compared to the manually-layered porcelain, the uniform surface quality of DVS-based glass ceramic ensured fewer defects, although this study performed no quantitative measurements for the comparison of defects. As DVS uses milled ceramic blocks, specimens fabricated using the DVS-based glass ceramic also had less firing-related shrinkage ${ }^{18)}$. Additionally, the coefficients of thermal expansion (CTEs) of DVS ceramic and fusion porcelain were slightly lower than that of the conventionally

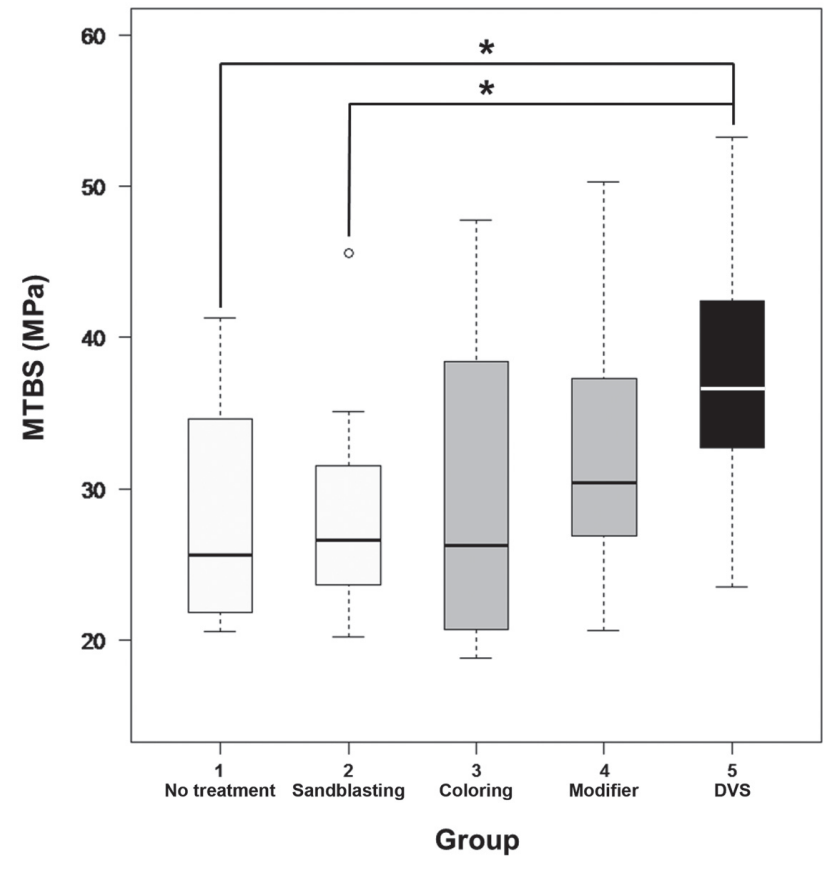

Fig. 2 Box plots for MTBS values of Group 1 (no treatment, negative control), Group 2 (sandblasting, positive control), Group 3 (coloring), Group 4 (modifier), and Group 5 (DVS).

MTBS values of Group 5 were significantly higher than those of Groups 1 and 2.

layered porcelain used in this study (Table 1), resulting in a larger difference from the CTE of the zirconiabased framework. After glass transition, DVS ceramic and fusion porcelain underwent greater compression, which might contribute to increased resistance to tensile forces ${ }^{19)}$.

To measure zirconia core-ceramic veneer bond strengths, shear bond strength test or MTBS test is typically used ${ }^{12-15)}$. Shear bond strength test is popular because of its simplicity and ease of specimen preparation. However, it does not actually measure bond strength; it measures the strength of the base material rather than 


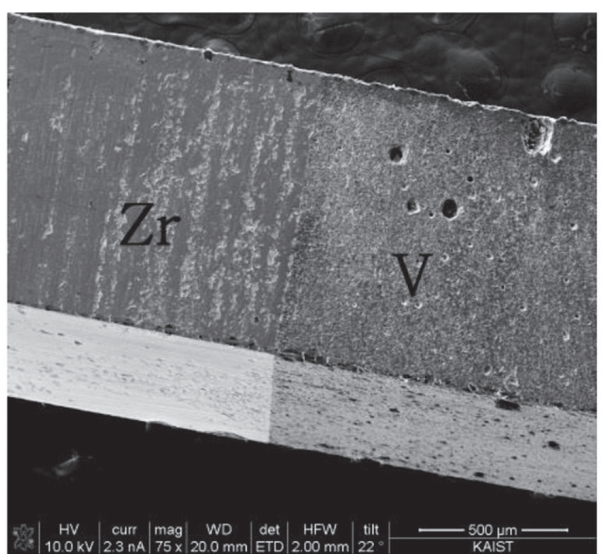

(a)

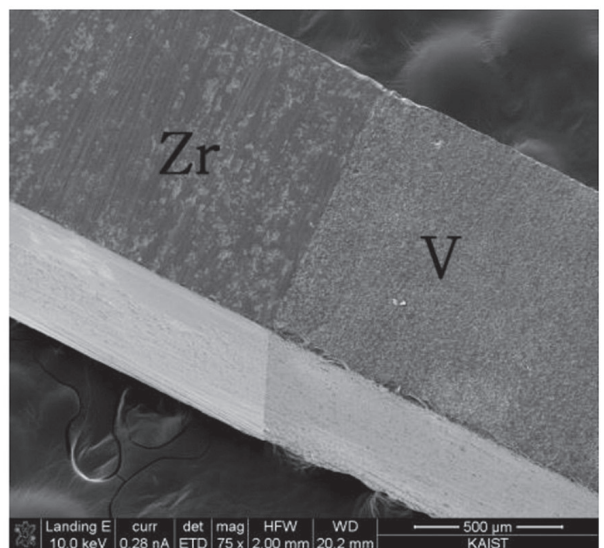

(c)

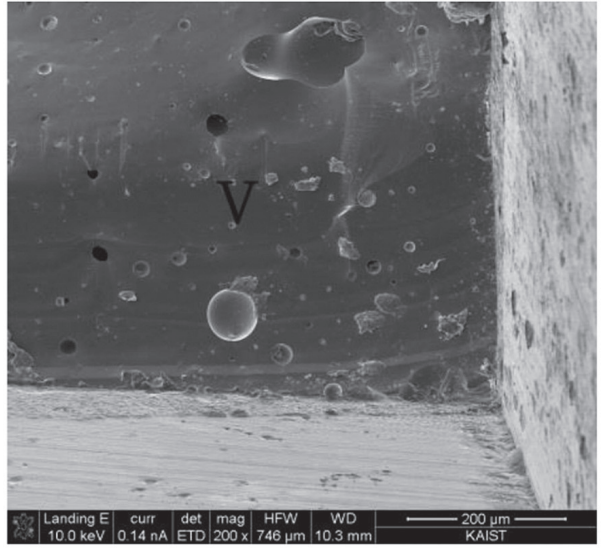

(e)

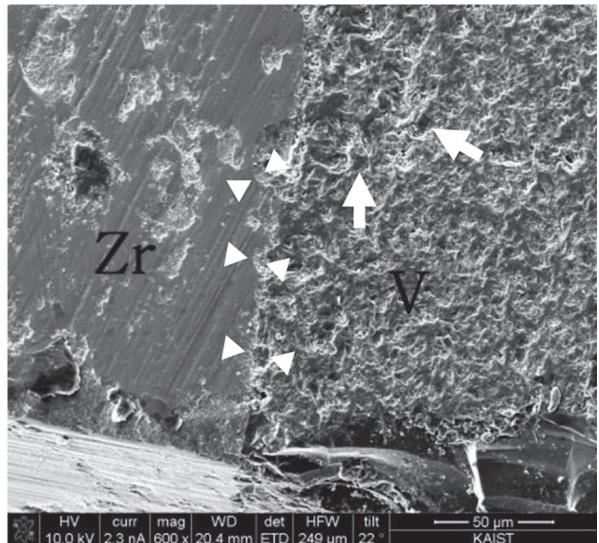

(b)

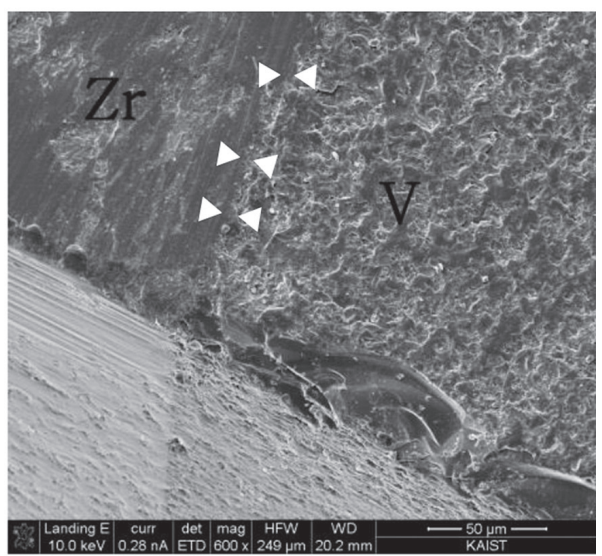

(d)

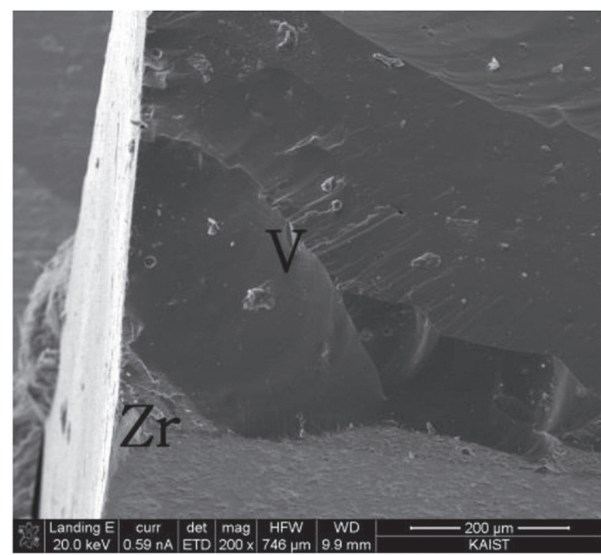

(f)

Fig. 3 SEM images of a microbar from Group 1 (negative control) before MTBS testing at $\times 75$ magnification (a) and $\times 600$ magnification (b). At low $(\times 75)$ magnification, there were seemingly no differences between Group 1 and DVS group (c) specimens. At high (×600) magnification, Group 1 specimen (b) showed larger gaps (white arrowheads) at the bonding interface and more defects (white arrows) in the ceramic than the DVS group (d). After MTBS testing, most specimens showed cohesive failure of the ceramic veneer (e). Some fractured microbars demonstrated mixed failures that exposed the broken surfaces of both the ceramic veneer and zirconia core (f). Exposure of the zirconia core surface was confirmed by EDS. Zr: zirconia core; V: ceramic veneer. 
the strength of the adhesive interface ${ }^{20)}$. It is also difficult to standardize shear bond strength tests because of the increase in bending moments, which is caused by the elevation of the location of applied point load ${ }^{21}$. In MTBS tests, the small size of the adhesive interface required for testing results in fewer defects and a more homogeneous interface when compared with the large interfacial area required for shear bond strength tests. Consequently, MTBS tests exhibit smaller coefficients of variance than the typically used shear or tensile bond strength tests $^{22,23)}$. However, MTBS test is time-consuming and technically sensitive due to the need for careful handling of fragile specimens ${ }^{24)}$. Special care needs to be taken during specimen preparation to prevent formation of microfractures at the core-veneer interface, which would weaken bond strength and distort results.

Similar to the results of previous studies ${ }^{25,26)}$, this study found that sandblasting of zirconia core had little effect on core-veneer bond strength. The sandblasting treatment did not cause any morphological changes in zirconia core surface because of the latter's hard and dense structure. The inherent hardness of zirconia and its resistance to abrasion could be explained by its sintering temperature $(1500 \mathrm{~K})$ and the resulting reduction in grain size (between 0.07 and $0.3 \mu \mathrm{m}$ ).

A coloring agent and a modifier were used in this study to change the color of the white zirconia framework. With the coloring agent, it was first dissolved in a solvent and then the milled framework was dipped in the coloring solution. With the modifier, a colored liner material was applied to the outer surface of the sintered white zirconia framework to change its color ${ }^{13)}$. The present study found indeterminate statistical results for these two agents. They showed no significant differences in MTBS when compared with either the controls (Groups 1 and 2) or the DVS group (Group 5), despite the DVS group having a significantly greater MTBS than both the negative and positive controls. Such indeterminacy was also observed in previous studies, thereby indicating that additional studies are needed to evaluate the effects of coloring agents and modifiers on bond strength ${ }^{13,15)}$.

Analysis of the fractured surfaces revealed that most specimens underwent cohesive failure, i.e., failure within the veneering ceramic. Therefore, bond strength between the zirconia core and ceramic veneer was stronger than the cohesive strength of the veneering ceramic itself, which then resulted in the chipping of the veneering ceramic $^{15)}$. Results of this study agreed with the findings of several clinical studies. It was numerously reported that chipping was the most frequently encountered clinical failure, although interfacial failures between zirconia cores and ceramic veneers were still encountered ${ }^{2-4,27-299}$.

In the present study, the authors did not investigate the effects of aging by thermocycling on bond strength, which would make the experimental condition more analogous to the oral environment. These effects need to be investigated as they may have probable influence on bond strength under clinical circumstances.

\section{CONCLUSIONS}

With DVS, ceramic veneer produced by computer-aided milling was fused to a zirconia core. Compared with the other surface treatments which used a coloring agent and a modifier and which did not significantly increase bond strength, DVS significantly improved the bond strength between the zirconia core and ceramic veneer. SEM observation of DVS-based fractured surfaces also suggested that the interfacial bond between the ceramic veneer and untreated core was stronger than the cohesive strength within the veneer. However, conditions in actual clinical situations, such as the aging of ceramic restorations, need to be simulated and investigated.

\section{REFERENCES}

1) Kosmac T, Oblak C, Jevnikar P, Funduk N, Marion L. The effect of surface grinding and sandblasting on flexural strength and reliability of Y-TZP zirconia ceramic. Dent Mater 1999; 15: 426-433.

2) Roediger M, Gersdorff N, Huels A, Rinke S. Prospective evaluation of zirconia posterior fixed partial dentures: fouryear clinical results. Int J Prosthodont 2010; 23: 141-148.

3) Sailer I, Feher A, Filser F, Gauckler LJ, Luthy H, Hammerle $\mathrm{CH}$. Five-year clinical results of zirconia frameworks for posterior fixed partial dentures. Int J Prosthodont 2007; 20: 383-388.

4) Sailer I, Feher A, Filser F, Luthy H, Gauckler LJ, Scharer P, Franz Hammerle CH. Prospective clinical study of zirconia posterior fixed partial dentures: 3-year follow-up. Quintessence Int 2006; 37: 685-693.

5) White SN, Miklus VG, McLaren EA, Lang LA, Caputo AA. Flexural strength of a layered zirconia and porcelain dental all-ceramic system. J Prosthet Dent 2005; 94: 125-131.

6) Griffin JD Jr. Combining monolithic zirconia crowns, digital impressioning, and regenerative cement for a predictable restorative alternative to PFM. Compend Contin Educ Dent 2013; 34: 212-222.

7) Kim HK, Kim SH, Lee JB, Han JS, Yeo IS. Effect of polishing and glazing on the color and spectral distribution of monolithic zirconia. J Adv Prosthodont 2013; 5: 296-304.

8) Zhang Y, Lee JJ, Srikanth R, Lawn BR. Edge chipping and flexural resistance of monolithic ceramics. Dent Mater 2013; 29: 1201-1208.

9) al-Shehri SA, Mohammed H, Wilson CA. Influence of lamination on the flexural strength of a dental castable glass ceramic. J Prosthet Dent 1996; 76: 23-28.

10) De Jager N, Pallav P, Feilzer AJ. The influence of design parameters on the FEA-determined stress distribution in CAD-CAM produced all-ceramic dental crowns. Dent Mater 2005; 21: 242-251.

11) Isgro G, Pallav P, van der Zel JM, Feilzer AJ. The influence of the veneering porcelain and different surface treatments on the biaxial flexural strength of a heat-pressed ceramic. J Prosthet Dent 2003; 90: 465-473.

12) Aboushelib MN, Kleverlaan CJ, Feilzer AJ. Microtensile bond strength of different components of core veneered allceramic restorations. Part II: Zirconia veneering ceramics. Dent Mater 2006; 22: 857-863.

13) Aboushelib MN, Kleverlaan CJ, Feilzer AJ. Effect of zirconia type on its bond strength with different veneer ceramics. J Prosthodont 2008; 17: 401-408.

14) Aboushelib MN, Kleverlaan CJ, Feilzer AJ. Microtensile bond strength of different components of core veneered all-ceramic restorations. Part 3: double veneer technique. J Prosthodont 2008; 17: 9-13. 
15) Fischer J, Grohmann P, Stawarczyk B. Effect of zirconia surface treatments on the shear strength of zirconia/veneering ceramic composites. Dent Mater J 2008; 27: 448-454.

16) Sundh A, Molin M, Sjogren G. Fracture resistance of yttrium oxide partially-stabilized zirconia all-ceramic bridges after veneering and mechanical fatigue testing. Dent Mater 2005; 21: 476-482.

17) Brawek PK, Wolfart S, Endres L, Kirsten A, Reich S. The clinical accuracy of single crowns exclusively fabricated by digital workflow - the comparison of two systems. Clin Oral Investig 2013; 17: 2119-2125.

18) Zeighami S, Mahgoli H, Farid F, Azari A. The effect of multiple firings on microtensile bond strength of core-veneer zirconia-based all-ceramic restorations. J Prosthodont 2013; 22: 49-53.

19) Isgro G, Kleverlaan CJ, Wang H, Feilzer AJ. Thermal dimensional behavior of dental ceramics. Biomaterials 2004; 25: 2447-2453.

20) Della Bona A, van Noort R. Shear vs. tensile bond strength of resin composite bonded to ceramic. J Dent Res 1995; 74: 1591-1596.

21) Van Noort R, Noroozi S, Howard IC, Cardew G. A critique of bond strength measurements. J Dent 1989; 17: 61-67.

22) Cardoso PE, Braga RR, Carrilho MR. Evaluation of microtensile, shear and tensile tests determining the bond strength of three adhesive systems. Dent Mater 1998; 14: 394-398.

23) Sano H, Shono T, Sonoda H, Takatsu T, Ciucchi B, Carvalho
R, Pashley DH. Relationship between surface area for adhesion and tensile bond strength - evaluation of a microtensile bond test. Dent Mater 1994; 10: 236-240.

24) Valandro LF, Ozcan M, Amaral R, Vanderlei A, Bottino MA. Effect of testing methods on the bond strength of resin to zirconia-alumina ceramic: microtensile versus shear test. Dent Mater J 2008; 27: 849-855.

25) Borges GA, Sophr AM, de Goes MF, Sobrinho LC, Chan DC. Effect of etching and airborne particle abrasion on the microstructure of different dental ceramics. J Prosthet Dent 2003; 89: 479-488.

26) Casucci A, Mazzitelli C, Monticelli F, Toledano M, Osorio R, Osorio E, Papacchini F, Ferrari M. Morphological analysis of three zirconium oxide ceramics: Effect of surface treatments. Dent Mater 2010; 26: 751-760.

27) Heintze SD, Rousson V. Survival of zirconia- and metalsupported fixed dental prostheses: a systematic review. Int $J$ Prosthodont 2010; 23: 493-502.

28) Koenig V, Vanheusden AJ, Le Goff SO, Mainjot AK. Clinical risk factors related to failures with zirconia-based restorations: an up to 9-year retrospective study. J Dent 2013; 41: 1164-1174.

29) Pelaez J, Cogolludo PG, Serrano B, Serrano JF, Suarez MJ. A four-year prospective clinical evaluation of zirconia and metal-ceramic posterior fixed dental prostheses. Int J Prosthodont 2012; 25: 451-458. 